\title{
Molecular Imaging of Bone Metastases and Their Response to Therapy
}

\author{
Gary J.R. Cook and Vicky Goh \\ Cancer Imaging Department, School of Biomedical Engineering and Imaging Sciences, King's College London, London, \\ United Kingdom
}

Learning Objectives: On successful completion of this activity, participants should understand (1) the pathophysiology of bone metastases that relates to imaging; (2) the strengths and weaknesses of bone-specific and tumor-specific imaging methods for bone metastases; and (3) the strengths and weaknesses of conventional imaging and the improvements that molecular and hybrid imaging offer.

Financial Disclosure: Dr. Cook was a coinvestigator in the FALCON trial (NCT02578940). Financial support was received from the Department of Health via the National Institute for Health Research (NIHR) Biomedical Research Centre awards to Guy's \& St. Thomas' NHS Foundation Trust in partnership with King's College London. Support was also received from the King's College London/University College London Comprehensive Cancer Imaging Centres, funded by Cancer Research U.K. and the Engineering and Physical Sciences Research Council in association with the Medical Research Council and the Department of Health (England). In addition, a research grant was received from Breast Cancer Now. The authors of this article have indicated no other relevant relationships that could be perceived as a real or apparent conflict of interest.

CME Credit: SNMMI is accredited by the Accreditation Council for Continuing Medical Education (ACCME) to sponsor continuing education for physicians. SNMMI designates each JNM continuing education article for a maximum of 2.0 AMA PRA Category 1 Credits. Physicians should claim only credit commensurate with the extent of their participation in the activity. For CE credit, SAM, and other credit types, participants can access this activity through the SNMMI website (http://www.snmmilearningcenter.org) through June 2023.

Bone metastases are common, especially in more prevalent malignancies such as breast and prostate cancer. They cause significant morbidity and draw on health-care resources. Molecular and hybrid imaging techniques, including SPECT/CT, PET/CT, and whole-body MRI with diffusionweighted imaging, have improved diagnostic accuracy in staging the skeleton compared with previous standard imaging methods, allowing earlier tailored treatment. With the introduction of several effective treatment options, it is now even more important to detect and monitor response in bone metastases accurately. Conventional imaging, including radiographs, CT, MRI, and bone scintigraphy, are recognized as being insensitive and nonspecific for response monitoring in a clinically relevant time frame. Early reports of molecular and hybrid imaging techniques, as well as whole-body MRI, promise an earlier and more accurate prediction of response versus nonresponse but have yet to be adopted routinely in clinical practice. We summarize the role of new molecular and hybrid imaging methods, including SPECT/CT, PET/CT, and whole-body MRI. These modalities are associated with improvements in diagnostic accuracy for the staging and response assessment of skeletal metastases over standard imaging methods, being able to quantify biologic processes related to the bone microenvironment as well as tumor cells. The described improvements in the imaging of bone metastases and their response to therapy have led to adoption of some of these methods into routine clinical practice in some centers. These methods also provide a better way to assess the treatment response of bone metastases in clinical trials.

Key Words: bone metastases; bone scintigraphy; SPECT/CT; PET/ CT; whole-body MRI

J Nucl Med 2020; 61:799-806

DOI: 10.2967/jnumed.119.234260

Received Feb. 3, 2020; revision accepted Mar. 30, 2020.

For correspondence or reprints contact: Gary Cook, Clinical PET Centre, St. Thomas' Hospital, London, SE1 7EH, U.K.

E-mail: gary.cook@kcl.ac.uk

Published online Apr. 3, 2020.

COPYRIGHT (C 2020 by the Society of Nuclear Medicine and Molecular Imaging.
B increased risk of skeletal-related events, including pathologic fracture and spinal cord compression, that may need radiotherapy or surgery for pain or impending fracture. Morbidity may also be associated with bone marrow suppression and hypercalcemia. Bone metastases are common in two of the most prevalent cancers, that is, breast and prostate cancer, for which up to $65 \%-90 \%$ and $65 \%-75 \%$, respectively, of patients with advanced disease may be affected (1). There is some evidence that patients with bone-predominant metastatic disease have better survival than those with visceral disease and that oligometastatic disease has a more favorable prognosis, implying that early diagnosis may affect outcomes. The introduction of molecular and hybrid imaging techniques has improved sensitivity for bone metastasis detection, but there remains uncertainty as to which modality is optimal in each type of cancer.

With the introduction of several novel therapeutics for metastatic prostate and breast cancer, and a requirement for more personalized and nuanced decisions on the correct management strategy, it has become even more important that bone metastases be detected earlier so that therapy that reduces skeletal-related events can be instigated. In particular, the trend toward treating oligometastatic disease with curative intent relies on sensitive diagnostics (2). Despite improved systemic therapeutics, response rates remain generally less than $50 \%$. Therefore, it is important that nonresponding patients be identified as soon as possible, allowing a transition to second-line therapy, to avoid potential toxicity from ineffective treatment and to optimally manage health-care costs $(3,4)$. This is especially important in metastatic breast and prostate cancers, for which survival tends to be longer than in patients with bone metastases from other cancers, with a subsequently greater impact on long-term morbidity and health-care costs.

Imaging, and in particular molecular and hybrid imaging, has an increasing role in detecting bone metastases early in their evolution and in monitoring treatment response at early time points (Table 1) $(5,6)$. 
TABLE 1

Radiopharmaceuticals and Their Clinical Utility in Imaging Bone Metastases

\begin{tabular}{|c|c|c|c|c|c|}
\hline Agent & Mechanism & $\begin{array}{l}\text { Usual injected } \\
\text { activity (MBq) }\end{array}$ & $\begin{array}{l}\text { Scan time } \\
\text { after injection }\end{array}$ & Clinical utility & References \\
\hline 99mTc-MDP & Bone & $600-1,110$ & $2-5 \mathrm{~h}$ & $\begin{array}{l}\text { Staging, restaging, } \\
\text { response assessment }\end{array}$ & $5,6,8,9,16,18,23,24,25,26$ \\
\hline${ }^{18} \mathrm{~F}$-fluoride & Bone & $185-370$ & $30-120 \mathrm{~min}$ & $\begin{array}{l}\text { Staging, response } \\
\text { assessment, prognosis }\end{array}$ & $\begin{array}{c}6,14,16,18,27,28,29,30,31 \\
32,33,34,35,37,45,50\end{array}$ \\
\hline${ }^{18} \mathrm{~F}-\mathrm{FDG}$ & Tumor & $370-740$ & 45-90 min & $\begin{array}{l}\text { Staging, restaging, response } \\
\text { assessment, prognosis }\end{array}$ & $\begin{array}{l}5,6,14,18,31,38,39,40,41 \\
\quad 42,43,44,45,47\end{array}$ \\
\hline${ }^{11} \mathrm{C}$-choline & Tumor & $370-740$ & $2-5 \min$ & $\begin{array}{l}\text { Staging, restaging, } \\
\text { response assessment }\end{array}$ & $48,50,51,54,69$ \\
\hline${ }^{18} \mathrm{~F}$-choline & Tumor & 370 & $60 \mathrm{~min}$ & $\begin{array}{l}\text { Staging, restaging, } \\
\text { response assessment }\end{array}$ & $49,50,52,53,55,56$ \\
\hline${ }^{18} \mathrm{~F}$-fluciclovine & Tumor & 370 & $3-5 \min$ & Restaging & 21 \\
\hline${ }^{68} \mathrm{Ga}-\mathrm{PSMA}$ & Tumor & $100-200$ & $50-100 \mathrm{~min}$ & Staging, restaging & $22,57,58,59$ \\
\hline
\end{tabular}

Bone scintigraphy with ${ }^{99 \mathrm{~m}} \mathrm{Tc}$-labeled diphosphonates such as ${ }^{99 \mathrm{~m}}$ Tc-methylene diphosphonate ( $\left.{ }^{99 \mathrm{~m}} \mathrm{Tc}-\mathrm{MDP}\right)$ has been used since the 1970s for detecting skeletal metastases and monitoring therapy, but sensitivity and specificity are known to be limited at staging and for monitoring treatment response. Conventional imaging, such as radiography, CT, or MRI, that relies on size-based criteria (e.g., RECIST (7)) for assessing treatment response is also limited, as bone disease is usually considered nonmeasurable unless associated with a measurable soft-tissue component. Attempts have been made to incorporate bone scintigraphy with other imaging in breast cancer (8) and prostate cancer (9) to improve response assessment, but early assessment within a clinically relevant time frame remains problematic in clinical practice. For example, the Prostate Cancer Working Group criteria primarily aim to determine disease progression, requiring at least 2 new lesions on the first assessment after a baseline bone scan and then at least a further 2 lesions on a subsequent confirmatory scan before progressive disease is confirmed (9). Scans are recommended every 8-9 wk for the first $24 \mathrm{wk}$ and every $12 \mathrm{wk}$ thereafter.

The combination of either tumor- or bone-specific radiotracers with CT or MRI in hybrid scanners such as SPECT/CT, PET/CT, or PET/MRI has potential to improve diagnosis and response assessment through synergy between morphologic and molecular information. However, despite the potential for gathering multiparametric information from metastases to clarify the diverse underlying biologic and morphologic tumor characteristics, there have been relatively few studies that have investigated ways to exploit these potential benefits.

The purpose of this educational review is to update the reader on the current status of functional and hybrid imaging, particularly PET and functional MRI methods, in detecting bone metastases and monitoring their response to therapy.

\section{PATHOPHYSIOLOGY OF BONE METASTASES RELEVANT TO IMAGING}

Paget's "seed and soil" hypothesis, that metastatic cancer cells preferentially deposit in the marrow microenvironment, in which they grow and eventually cause bone destruction, is relevant to skeletal metastasis imaging (10) because there is an opportunity to detect early marrow-based disease before a reaction in the bone microenvironment has occurred. This detection requires bone marrow-specific or tumor-specific imaging methods such as whole-body MRI with diffusion-weighted imaging or ${ }^{18}$ F-FDG PET. These have shown greater sensitivity than methods that require increased osteoblastic activity (e.g., radiography, CT, bone scintigraphy, and ${ }^{18} \mathrm{~F}$-fluoride PET), which is a later event.

The biologic and morphologic characteristics of treatmentnaïve bone metastases vary on a spectrum from predominantly lytic to predominantly sclerotic, although both processes are usually present to some extent. Osteolytic metastases are commoner in most cancers (e.g., breast and lung). In osteolytic metastases, cancer cells produce a parathyroid hormone-related protein that induces osteoblasts to produce a receptor activator of nuclear factor $\kappa \mathrm{B}$ ligand, which stimulates osteoclast maturation and activity (11). Increased osteoclast activity leads to localized bone resorption exceeding the reparative ability of osteoblasts and releases factors from the bone matrix that stimulate parathyroid hormone-related protein production, thereby creating a vicious cycle. The resultant lytic lesions lead to the morbidity associated with bone metastases and skeletal-related events.

In some cancers, such as prostate cancer, an osteoblastic phenotype predominates. Tumor-derived growth factors stimulate primarily osteoblasts rather than osteoclasts. Excess abnormal bone is laid down, with resultant sclerosis on radiographs and CT and increased activity on bone-specific nuclear medicine methods such as bone scintigraphy with ${ }^{99 \mathrm{~m}} \mathrm{Tc}-\mathrm{MDP}$ or ${ }^{18} \mathrm{~F}$-fluoride PET.

Osteoblast activity may also increase as a reparative process in successfully treated bone metastases such that both lytic and sclerotic lesions become denser on radiographs or CT scans (12). This phenomenon can also lead to an increase in uptake of bonespecific tracers such as ${ }^{99 \mathrm{~m}} \mathrm{Tc}-\mathrm{MDP}$ or ${ }^{18} \mathrm{~F}$-fluoride. The so-called flare phenomenon, which causes an increase in activity in preexisting metastases for several weeks or months, or the appearance of previously occult metastases after successful systemic therapy, has been well described and if seen is associated with an improved 
prognosis $(13,14)$. This is due to an increase in reparative osteoblastic activity as the bone surrounding metastatic tumor cells heals after tumoricidal therapy.

Bone metastasis imaging can be divided into bone-specific or tumor-specific modalities, whether morphologic or functional. Morphologic methods that rely mostly on changes to bone density include radiography or CT, although tumor-related soft tissue can also sometimes be appreciated on CT. Bone-specific nuclear medicine methods include bone scintigraphy (e.g., ${ }^{99 \mathrm{~m}}$ Tc-MDP with or without SPECT or SPECT/CT) and ${ }^{18} \mathrm{~F}-$ fluoride PET/CT. Accumulation of these tracers reflects local blood flow and mineralization due to osteoblast activity (15). Although these agents rely predominantly on an osteoblastic mechanism for uptake and are therefore most sensitive in cancers associated with an osteoblastic phenotype (e.g., prostate cancer), most cancers associated with an osteolytic metastatic phenotype also show accumulation because there is usually an accompanying osteoblastic component (11). Some skeletal malignancies, such as myeloma, are predominantly osteolytic with suppressed bone formation, and hence bone scintigraphy or ${ }^{18} \mathrm{~F}$-fluoride PET may be relatively insensitive compared with tumor-specific methods.

Tumor-specific imaging methods that take advantage of different biologic characteristics in tumor cells to provide contrast in the image include MRI, as well as PET and SPECT methods that use metabolic or receptor-targeting tracers.

Conventional MRI sequences (e.g., T1-weighted, T2-weighted, and short-tau inversion recovery), reflecting differences in proton density (i.e., water), detect tumor tissue within bone marrow and any soft-tissue component invading bone. The diffusion-weighted MRI signal depends on restricted motion of water molecules and can be quantified by measuring the apparent diffusion coefficient, allowing serial measurements to monitor treatment response (16). Tumors that are usually more highly cellular than normal tissues or normal bone marrow show greater restriction of water molecule motion. During successful treatment, water molecule motion becomes less restricted as the tumors become less cellular, and this effect can be seen through an increase in apparent diffusion coefficient. It is now possible to perform whole-body MRI with conventional

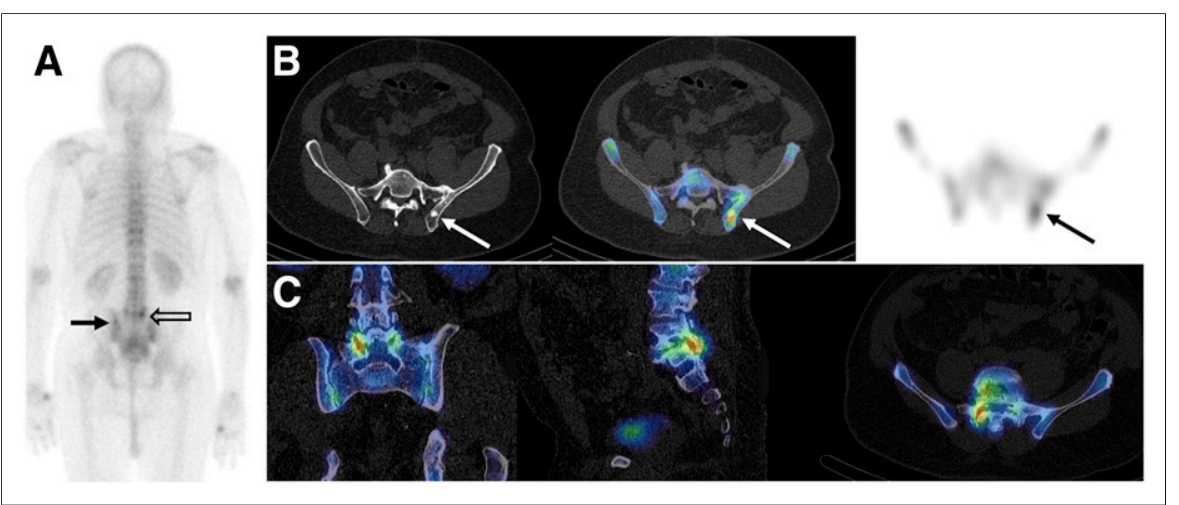

FIGURE 1. Patient with high-risk newly diagnosed prostate cancer. (A) ${ }^{99 m T c-M D P ~ p o s t e r i o r ~ p l a n a r ~}$ bone scan. (B) From left to right: transaxial CT, SPECT/CT, and SPECT images through iliac bones. (C) From left to right, coronal, sagittal, and transaxial SPECT/CT images of lower lumbar spine. Metastasis showing CT sclerosis and ${ }^{99 m}$ Tc-MDP uptake is faintly visible on planar image (solid arrow) but is more clearly shown on SPECT/CT images (arrows). In contrast, abnormal activity in lower lumbar spine on planar image (open arrow) can be seen to relate to benign facet joint changes on SPECT/CT images. sequences and diffusion-weighted imaging in less than $1 \mathrm{~h}$, and this method is now more frequently used to detect and monitor skeletal metastases. More recently, ultrashort-echo-time MRI sequences have also shown promise in depicting the bone microstructure in humans and the changes in mineralization upon therapy in animal models (17).

Molecular imaging methods for evaluating bone metastases include metabolic tracers such as, most commonly, ${ }^{18} \mathrm{~F}-\mathrm{FDG}$ $(5,6,18)$. Uptake of ${ }^{18} \mathrm{~F}$-FDG is enhanced in most malignant tumor cells by the Warburg effect, resulting in increased glycolysis rather than oxidative metabolism (19). An increase in glucose membrane transporters and phosphorylation by hexokinase II leads to a higher ${ }^{18} \mathrm{~F}$-FDG tumor accumulation than in normal cells. Alternative metabolic tracers such as ${ }^{18} \mathrm{~F}$ - or ${ }^{11} \mathrm{C}$-choline (choline kinase activity and cell membrane turnover) may be used in tumors such as prostate cancer that do not tend to show increased glycolysis (16).

Another metabolic PET tracer that has been licensed for biochemical recurrence of prostate cancer is ${ }^{18} \mathrm{~F}$-fluciclovine. This synthetic amino acid analog of leucine shows increased uptake in tumor cells, reflecting increased amino acid transport, protein, and nucleotide synthesis. There are preclinical and clinical reports of successful imaging of bone metastases with ${ }^{18} \mathrm{~F}$-fluciclovine $(20,21)$ despite normal diffuse bone marrow uptake. Other tracers that have shown efficacy in skeletal and soft-tissue metastases include those targeting specific receptors or antigens. Small-molecule inhibitors of prostate-specific membrane antigen (PSMA) labeled with ${ }^{68} \mathrm{Ga}$ show little normal bone marrow activity and are associated with good tumor-to-background contrast in bone metastases (22).

\section{BONE-SPECIFIC IMAGING}

\section{Bone Scintigraphy, Including SPECT and SPECT/CT}

Bone scintigraphy with ${ }^{99 \mathrm{~m}} \mathrm{Tc}$-radiolabeled diphosphonates started in the 1970s. These tracers showed rapid clearance from blood and soft tissues with resultant good image contrast as early as $2 \mathrm{~h}$ after injection (23). Although widely used for many decades for detecting and monitoring skeletal metastases, it is recognized that alternative modern imaging techniques are more sensitive and specific $(5,6,16,18)$. However, the advent of SPECT image acquisition, and then hybrid imaging with SPECT/CT, has prolonged the life of bone scintigraphy. These hardware and reconstruction modifications improve both sensitivity (better contrast resolution) and specificity (3-dimensional display of data with CT anatomic correlate) $(24,25)$. Combining CT morphologic characteristics improves the specificity of bone scintigraphy, with more accurate characterization of benign and malignant hot spots, an increase in confidence in scan interpretation, and fewer equivocal studies (Fig. 1) (25).

Bone scintigraphy is recognized as being relatively insensitive and nonspecific in the evaluation of systemic treatment response in skeletal metastases, often requiring several weeks or months before response can be confirmed (26). The flare phenomenon can make it impossible to differentiate progressive 
disease from a healing osteoblastic response for several weeks or months after chemotherapy or endocrine therapy. However, recognition of a flare is a good prognostic sign (13).

\section{${ }^{18}$ F-Fluoride PET/CT}

${ }^{18} \mathrm{~F}$-fluoride was first described as a bone-specific tracer in 1962 , but because the high-energy 511-keV photons are unsuited to $\gamma$-camera imaging, ${ }^{18} \mathrm{~F}$-fluoride was not used clinically to much extent until the advent of modern PET and PET/CT scanners. Periodic shortages of ${ }^{99 \mathrm{~m}} \mathrm{Tc}$ generators have also led to an increase in the use of ${ }^{18} \mathrm{~F}$-fluoride for functional bone imaging.

Regional accumulation of the tracer in the skeleton depends on local blood flow and mineralization activity, with fluoride ions replacing hydroxyl ions in hydroxyapatite crystals to form fluoroapatite in bone mineral. With rapid clearance of softtissue background activity by renal excretion, and nearly a $100 \%$ first-pass extraction by bone, good skeleton-to-background contrast can be achieved as early as $1 \mathrm{~h}$ after injection (Fig. 2A) (15).

PET has the advantage of accurate and absolute quantification of tracer concentration, and although not generally suited to the clinic, PET is able to measure lesion blood flow $\left(K_{1}\right.$, or ${ }^{18} \mathrm{~F}$-fluoride clearance from plasma to bone tissue) and mineralization activity ( $K_{i}$, or plasma clearance to the bone mineral compartment) (15). These kinetic indices require dynamic acquisitions and direct or indirect measurement of the arterial plasma concentration of ${ }^{18} \mathrm{~F}$-fluoride over time. Dynamic scans are generally limited to the length of the $z$-axis of the PET scanner field of view and therefore are not suited to whole-body bone metastasis assessment. However, the kinetic method has been shown to be feasible as an adjunct to whole-body imaging in breast cancer-related bone metastases (27) and as a method to measure the response to dasatinib by prostate cancer bone metastases (28). To overcome the limited field of view for dynamic studies, a static whole-skeleton scan method has been developed that measures $K_{i}$ with the requirement for only 2 venous blood samples. This method was better than SUV at differentiating responders from nonresponders in a small cohort of breast cancer patients with bone-predominant metastatic disease (29).
The superior contrast and spatial resolution of ${ }^{18} \mathrm{~F}$-fluoride PET/ CT, compared with bone scintigraphy with or without SPECT or $\mathrm{CT}$, allows better diagnostic accuracy in detecting skeletal metastases in prostate, breast, lung, and other cancers (30,31). As with bone scintigraphy, uptake of ${ }^{18} \mathrm{~F}$-fluoride is not specific to metastases, and benign bone lesions can cause false-positives. However, specificity is improved by the ability to compare morphologic characteristic on the CT component. In a National Oncology PET Registry trial of 3,531 patients with prostate cancer, ${ }^{18} \mathrm{~F}$-fluoride PET/CT changed management from nontreatment to treatment in $47 \%$ of patients at initial staging, $44 \%$ of patients with a suspected first bone metastasis, and $52 \%$ of patients with suspected progressive disease (32). Similar significant changes in management were also seen in a further National Oncology PET Registry study of patients with breast, lung, and other cancers (33).

The value of ${ }^{18} \mathrm{~F}$-fluoride PET/CT in monitoring treatment response is less well described. However, early studies have shown potential for this application in patients treated with ${ }^{223} \mathrm{Ra}$-chloride (34) and the ability to predict the absorbed dose before therapy (35) and the risk of bone marrow toxicity from this treatment (36). Because both ${ }^{18} \mathrm{~F}$-fluoride and ${ }^{223} \mathrm{Ra}$-chloride share an osteoblastic mechanism of bone uptake, ${ }^{18} \mathrm{~F}$-fluoride PET is well suited as a theranostic agent in this setting.

A study of breast cancer patients treated with endocrine-based therapy showed that an increase in $\mathrm{SUV}_{\max }$ on ${ }^{18} \mathrm{~F}$-fluoride PET/ $\mathrm{CT}$ at 8 wk could predict subsequent progressive disease with modest sensitivity $(60 \%)$ but could not be reliably differentiated from a flare in patients who ultimately responded (14). In another National Oncology PET Registry study evaluating ${ }^{18} \mathrm{~F}$-fluoride $\mathrm{PET} / \mathrm{CT}$, a change in management in $40 \%$ of patients with prostate, breast, or lung cancer was reported (37).

\section{TUMOR-SPECIFIC IMAGING}

\section{F-FDG PET/CT}

There is evidence that different bone metastasis phenotypes exhibit differences in ${ }^{18} \mathrm{~F}-\mathrm{FDG}$ avidity. Osteoblastic metastases show lower uptake than osteolytic lesions, and the ${ }^{18} \mathrm{~F}-\mathrm{FDG}$-avid

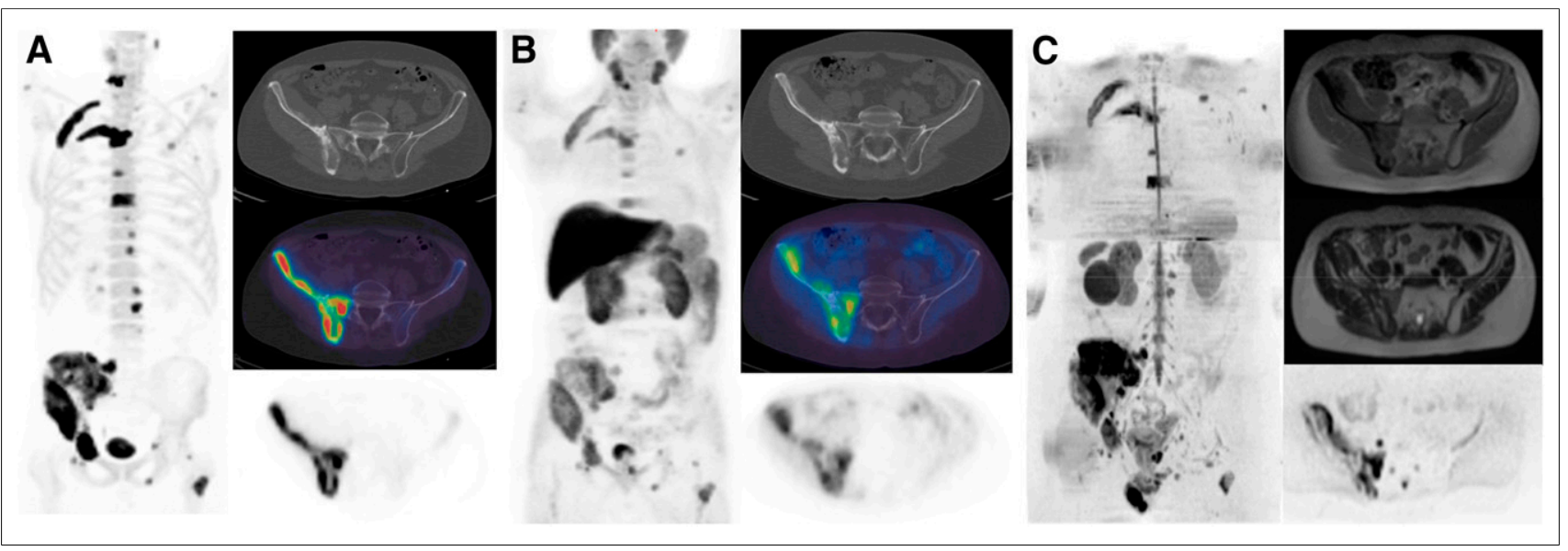

FIGURE 2. Patient with metastatic prostate cancer. (A and B) ${ }^{18} \mathrm{~F}$-fluoride $(\mathrm{A})$ and ${ }^{11} \mathrm{C}$-choline $(\mathrm{B})$ images, including maximum-intensity projection (left), transaxial pelvis CT (top right), PET/CT (middle right) and PET (bottom right). (C) MR maximum-intensity projection (high b value, b800 s/mm²) (left), transaxial pelvis T1-weighted Dixon MR image (top right), T2-weighted MR image (middle right), and b800 diffusion-weighted image (bottom right). Increased ${ }^{18} \mathrm{~F}$-fluoride and ${ }^{11} \mathrm{C}$-choline uptake is present in several bone metastases, corresponding to low signal on $\mathrm{T} 1$-weighted images, mixed signal on T2-weighted images, and high signal on b800 images. 
osteolytic phenotype may be associated with a worse prognosis (38). This observation has been reported mostly in breast cancer, for which the low glycolytic activity in osteoblastic lesions occurs in both treated and untreated metastases, especially in lobular breast cancer metastases (39). In most cancers, osteolytic metastases predominate, and several reports and metaanalyses have confirmed a greater sensitivity and specificity for detecting bone metastases with ${ }^{18} \mathrm{~F}$-FDG PET/CT than with bone scintigraphy, particularly in breast cancer $(38,40,41)$.

There is accumulating evidence that ${ }^{18} \mathrm{~F}-\mathrm{FDG}$ PET/CT may be helpful in monitoring systemic therapy (Fig. 3). There have been several small retrospective series reporting that changes in $\mathrm{SUV}_{\text {max }}$ can monitor treatment response and predict the time to skeletal-related events and to progression of breast cancer bone metastases (42-44). Two small prospective studies have confirmed that ${ }^{18} \mathrm{~F}-\mathrm{FDG} \mathrm{PET} / \mathrm{CT}$ is able to predict the time to skeletal-related events or the time to progression better than ${ }^{18} \mathrm{~F}$-fluoride, which can be hampered by the flare phenomenon $(14,45)$. In these studies, an increase in ${ }^{18} \mathrm{~F}$-fluoride uptake caused by the flare phenomenon could not be reliably differentiated from progressive disease at early time points. In contrast, although not commonly recognized with ${ }^{18} \mathrm{~F}-\mathrm{FDG}$, a metabolic flare has been reported in a small cohort of patients with lung cancer treated with the antiangiogenic agent bevacizumab when combined with chemotherapy (46). It is likely that some patients show a heterogeneity of response between different metastases with ${ }^{18} \mathrm{~F}$-FDG and ${ }^{18} \mathrm{~F}$-fluoride, an increasingly recognized phenomenon in cancer (14).

\section{${ }^{18} \mathrm{~F}$ - and ${ }^{11} \mathrm{C}$-Choline PET/CT}

${ }^{18} \mathrm{~F}-\mathrm{FDG}$ demonstrates low uptake in hormone-sensitive metastatic prostate cancer but may show higher uptake in castrationresistant prostate cancer, for which it has been used to monitor therapy response (47). For staging purposes, there has been interest in using alternative tracers with higher uptake. Prostate cancer is associated with upregulation of choline transport and choline kinase expression, with incorporation of choline into the membranes of proliferating tumor cells. Both ${ }^{11} \mathrm{C}$ and ${ }^{18} \mathrm{~F}$ labeling of choline has been described for staging high-risk prostate cancer at diagnosis and for evaluating biochemical recurrence (Fig. 2B). Active osteoblastic metastases show increased choline activity against the normal background bone marrow activity, and the rarer osteolytic phenotype shows even higher uptake (48). Choline PET/CT has shown better diagnostic accuracy than bone

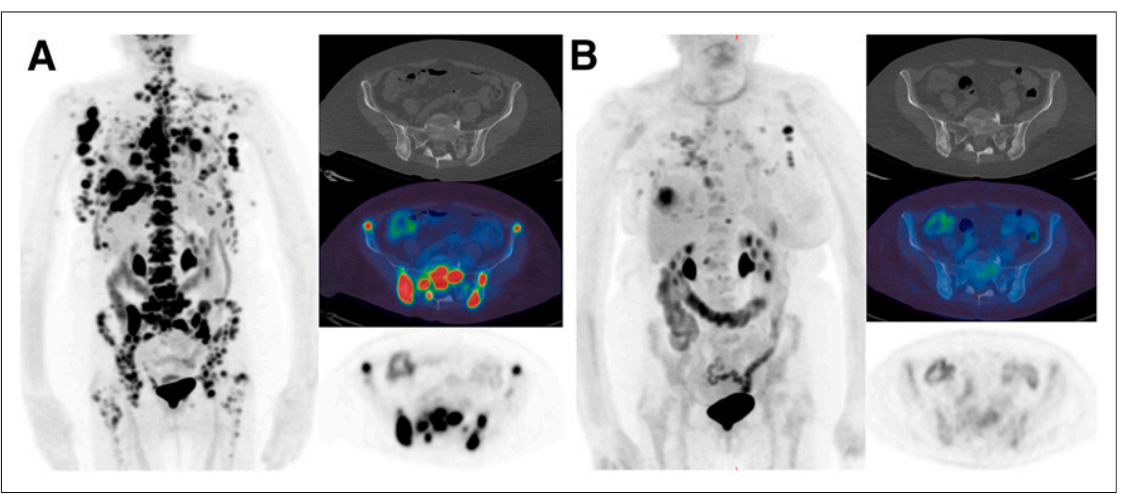

FIGURE 3. Patient with metastatic breast cancer. Shown are ${ }^{18} \mathrm{~F}-\mathrm{FDG}$ PET/CT scans before (A) and 8 wk after (B) commencing endocrine therapy, including maximum-intensity projection (left), transaxial pelvis CT image (top right), PET/CT image (middle right), and PET image (bottom right). Extensive bone and soft-tissue metastases show significant reduction in uptake at most sites, in keeping with treatment response. lliac bones appear slightly more sclerotic on CT component. scintigraphy for staging high-risk patients at diagnosis $(49,50)$ and for patients with biochemical recurrence (51).

When ${ }^{18} \mathrm{~F}$-choline has been compared with ${ }^{18} \mathrm{~F}$-fluoride for detection of skeletal metastases from prostate cancer, some small bone marrow lesions were visible with ${ }^{18} \mathrm{~F}$-choline but not with ${ }^{18} \mathrm{~F}$ fluoride (52). A further comparative cross-sectional study of patients who had bone metastases and were receiving hormone treatment showed that more of the sclerotic lesions with high Hounsfield units on CT were likely to be ${ }^{18} \mathrm{~F}$-choline-negative but ${ }^{18} \mathrm{~F}$-fluoride-positive. This finding implies that lesions responding to treatment show choline metabolism that is switched off but that reparative osteoblastic activity, as shown by CT sclerosis and ${ }^{18} \mathrm{~F}$-fluoride uptake, continues longer (53). The data on the use of choline PET tracers for monitoring treatment response in bone metastases are conflicting. A study of 32 patients with castration-resistant prostate cancer treated with docetaxel chemotherapy concluded that ${ }^{11} \mathrm{C}$-choline was of limited use for response assessment (54). Similarly, a study evaluating response to the antiandrogen effects of enzalutamide with ${ }^{18}$ F-choline PET/CT suggested no additional benefit over PSA in predicting overall survival (55). However, a separate study of patients treated with the antiandrogen abiraterone reported that ${ }^{18} \mathrm{~F}$-choline $\mathrm{PET} / \mathrm{CT}$ predicted progression-free and overall survival (56).

\section{${ }^{18}$ F-Fluciclovine PET/CT}

As an amino acid analog, ${ }^{18} \mathrm{~F}$-fluciclovine shows some background normal bone marrow activity. Nevertheless, preclinical data showing an ability to detect bone metastases (20) have been supported by subsequent clinical data showing superiority over bone scintigraphy (Fig. 4) (21). To date, the role for this agent in monitoring treatment response in bone metastases is unknown.

\section{${ }^{68}$ Ga-PSMA PET/CT}

Because PSMA tracers show minimal bone marrow activity, PSMA-expressing bone metastases are more conspicuous than ${ }^{18} \mathrm{~F}$ choline (Fig. 5) (22). Several studies have reported higher sensitivity than bone scintigraphy (57-59) and sensitivity similar to or better than that of ${ }^{18} \mathrm{~F}$-fluoride PET/CT $(57,60)$. These results suggest that if PSMA PET/CT imaging is performed, additional bone-specific imaging is not required in most patients $(58-60)$. However, 1 study showed a lower sensitivity for detecting bone metastases in patients with advanced disease scheduled for radionuclide therapy (61). These patients had received previous conventional treatments, and it is possible that a heterogeneous response, as has been described (62), had rendered the tumor cells in some metastases metabolically quiescent (PSMA-negative) but with continued reparative osteoblastic activity ( ${ }^{18} \mathrm{~F}$-fluoride-positive), as has been suggested in a comparison between ${ }^{18} \mathrm{~F}$-choline and ${ }^{18} \mathrm{~F}$-fluoride (53).

False-positives are rare, but ${ }^{68} \mathrm{Ga}$-PSMA uptake has been reported in Paget disease (63). Although data on the use of PSMA PET for monitoring response by bone metastases are scarce, a metabolic flare upon androgen deprivation therapy has been reported as a note of caution (64).

\section{Whole-Body MRI and Diffusion-Weighted Imaging}

Whole-body MRI acquisitions are now feasible in less than $1 \mathrm{~h}$, and with its lack 


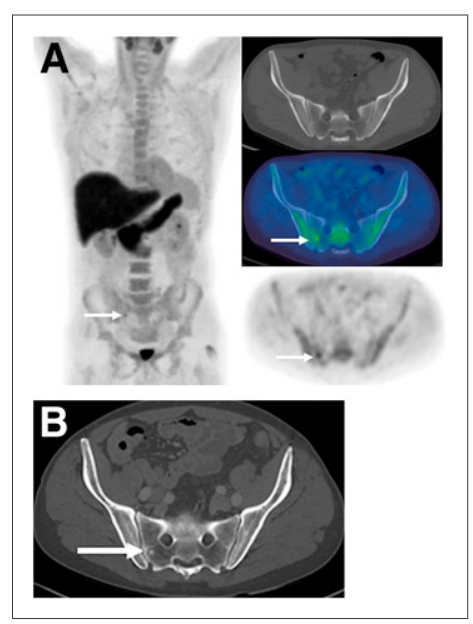

FIGURE 4. Patient with biochemica recurrence (PSA, $0.52 \mathrm{ng} / \mathrm{mL}$ ) $11 \mathrm{mo}$ after prostatectomy for Gleason $4+$ 5 prostate cancer. (A) ${ }^{18} \mathrm{~F}$-fluciclovine PET/CT maximum-intensity projection (left), transaxial pelvis CT image (top right), PET/CT image (middle right), and PET image (bottom right) are shown. Subtle focus of increased uptake is present on right side of sacrum (arrows) but is occult on CT component. After patient began hormone therapy, lesion became sclerotic in response $(B$, arrow). (Courtesy of Blue Earth Diagnostics Ltd.)

of ionizing radiation, high spatial and contrast resolution, and new functional sequences, this modality is being adopted clinically for imaging the skeleton for metastatic disease $(65,66)$. Several studies have reported high diagnostic accuracy in breast and prostate cancer, with accuracy similar to that of ${ }^{18} \mathrm{~F}$-fluoride, ${ }^{18} \mathrm{~F}-\mathrm{FDG}$, and ${ }^{11} \mathrm{C}$-choline PET/CT (67-70).

There is increasing interest in using diffusionweighted imaging in conjunction with morphologic sequences in whole-body MRI to provide a quantitative measure of treatment response in skeletal metastases. Successful therapy leads to breakdown of tumor cells, with loss of membrane integrity and cellularity, and a consequent increase in water diffusion in the extracellular space as measured by an increase in the apparent diffusion coefficient (5).

Early reports confirm that an increase in the apparent diffusion coefficient may predict a clinical treatment response in prostate cancer (71) and breast cancer (14).

A challenge with sclerotic bone lesions is that there are fewer protons to produce a signal, thus giving a low signal on T1- and T2-weighted images and a lower diffusion and apparent diffusion coefficient. There is a limitation is differentiating sclerosis after successful treatment from progressive disease, although this limitation has not been shown to have a significant negative diagnostic effect in prostate cancer (72).

\section{PET/MRI}

The MRI sequences performed as part of a whole-body MRI scan can be replicated in PET/MRI acquisitions. Early data suggest there are synergistic advantages to combining PET/MRI of the skeleton with ${ }^{18} \mathrm{~F}$-FDG (73), including an increase in anatomic delineation and diagnostic certainty in the evaluation of malignant bone lesions. Some inaccuracy in quantification of SUVs in skeletal lesions was also reported but is likely to become less significant with the development of new attenuation correction algorithms from MRI data. A potential weakness of PET/MRI compared with PET/ $\mathrm{CT}$ is that the CT component can give valuable additional information on bone lesion phenotype that MRI may be less able to provide.

\section{CONCLUSION}

Molecular and hybrid imaging of skeletal metastases can be divided into bone-specific and tumor-specific methods that have certain advantages and disadvantages depending on the

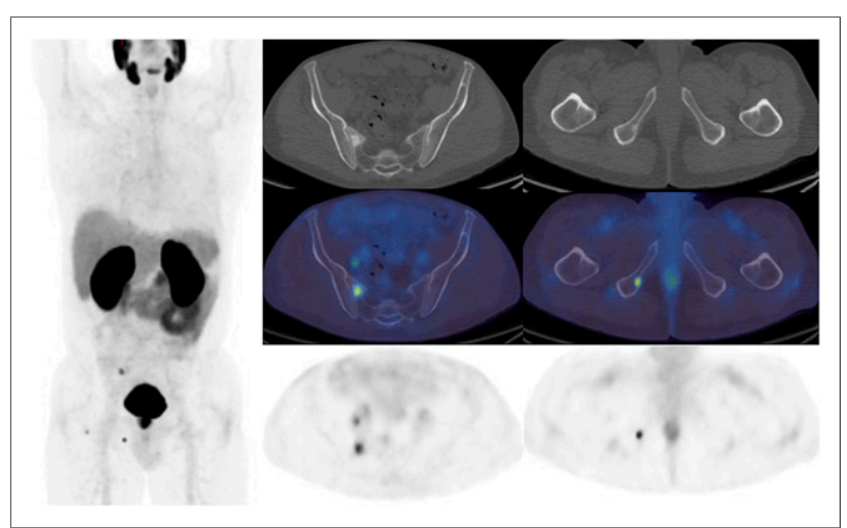

FIGURE 5. Patient with new diagnosis of Gleason $4+5$ prostate cancer (PSA, $20.8 \mathrm{ng} / \mathrm{mL}$ ). Shown are ${ }^{68} \mathrm{Ga}-\mathrm{PSMA} \mathrm{PET} / \mathrm{CT}$ images, including maximum-intensity projection (left), transaxial pelvis CT images (top row, right), PET/CT images (middle row, right), and PET images (bottom row, right). As well as increased uptake in prostate gland visible on maximum-intensity projection, there are focal areas of increased uptake corresponding to sclerotic lesions in right sacrum and right ischium. Further bone lesion is present in right hip on maximum-intensity projection, and uptake in right pelvic node is also visible on left transaxial PET and PET/CT images.

tumor phenotype and whether the application will be for staging or for response assessment. Improvements in scanning methodology with the advent of hybrid and new functional imaging methods, including SPECT/CT, PET/CT and whole-body MRI with diffusionweighted imaging, allow better sensitivity and specificity in detecting bone metastases than was previously possible. Early response assessment and prediction are improved with tumor-specific methods, but the optimal method in each cancer type and after different types of treatment requires further research before firm recommendations can be given.

\section{REFERENCES}

1. D'Oronzo S, Coleman R, Brown J, Silvestris F. Metastatic bone disease: pathogenesis and therapeutic option - up-date on bone metastasis management. J Bone Oncol. 2018;15:004.

2. Franklin JM, Sharma RA, Harris AL, Gleeson FV. Imaging oligometastatic cancer before local treatment. Lancet Oncol. 2016;17:e406-e414.

3. Mouridsen H, Gershanovich M, Sun Y, et al. Phase III study of letrozole versus tamoxifen as first-line therapy of advanced breast cancer in postmenopausal women: analysis of survival and update of efficacy from the International Letrozole Breast Cancer Group. J Clin Oncol. 2003;21:2101-2109.

4. Hoefeler H, Duran I, Hechmati G, et al. Health resource utilization associated with skeletal-related events in patients with bone metastases: results from a multinational retrospective-prospective observational study - a cohort from 4 European countries. J Bone Oncol. 2014;3:40-48.

5. Lecouvet FE, Talbot JN, Messiou C, Bourguet P, Liu Y, de Souza NM; EORTC Imaging Group. Monitoring the response of bone metastases to treatment with magnetic resonance imaging and nuclear medicine techniques: a review and position statement by the European Organisation for Research and Treatment of Cancer imaging group. Eur J Cancer. 2014;50:2519-2531.

6. Cook GJR, Goh V. Functional and hybrid imaging of bone metastases. J Bone Miner Res. 2018;33:961-972.

7. Eisenhauer EA, Therasse P, Bogaerts J, et al. New response evaluation criteria in solid tumours: revised RECIST guideline (version 1.1). Eur J Cancer. 2009;45: $228 \mathrm{e} 47$.

8. Hamaoka T, Costelloe CM, Madewell JE, et al. Tumour response interpretation with new tumour response criteria vs the World Health Organisation criteria in patients with bone-only metastatic breast cancer. Br J Cancer. 2010;102:651-657.

9. Scher HI, Morris MJ, Stadler WM, et al.; Prostate Cancer Clinical Trials Working Group 3. Trial design and objectives for castration-resistant prostate cancer: 
updated recommendations from the Prostate Cancer Clinical Trials Working Group 3. J Clin Oncol. 2016;34:1402-1418.

10. Paget S. The distribution of secondary growth in cancer of the breast. Lancet. 1889;1:571-573.

11. Guise TA, Mohammad KS, Clines G, et al. Basic mechanisms responsible for osteolytic and osteoblastic bone metastases. Clin Cancer Res. 2006;12:6213s-6216s.

12. Messiou C, Cook G, Reid AH, et al. The CT flare response of metastatic bone disease in prostate cancer. Acta Radiol. 2011;52:557-561.

13. Coleman RE, Mashiter G, Whitaker KB, Moss DW, Rubens RD, Fogelman I. Bone scan flare predicts successful systemic therapy for bone metastases. $\mathrm{J} \mathrm{Nucl}$ Med. 1988;29:1354-1359.

14. Azad GK, Taylor BP, Green A, et al. Prediction of therapy response in bonepredominant metastatic breast cancer: comparison of $\left[{ }^{18} \mathrm{~F}\right]$ fluorodeoxyglucose and $\left[{ }^{18} \mathrm{~F}\right]$-fluoride PET/CT with whole-body MRI with diffusion-weighted imaging. Eur J Nucl Med Mol Imaging. 2019;46:821-830.

15. Blake GM, Park-Holohan SJ, Cook GJ, Fogelman I. Quantitative studies of bone with the use of ${ }^{18} \mathrm{~F}$-fluoride and ${ }^{99 \mathrm{~m}} \mathrm{Tc}$-methylene diphosphonate. Semin Nucl Med. 2001;31:28-49.

16. Cook GJ, Azad G, Padhani AR. Bone imaging in prostate cancer: the evolving roles of nuclear medicine and radiology. Clin Transl Imaging. 2016;4:439-447.

17. Anumula S, Wehrli SL, Magland J, Wright AC, Wehrli FW. Ultra-short echotime MRI detects changes in bone mineralization and watercontent in OVX rat bone in response to alendronate treatment. Bone. 2010;46:1391-1399.

18. Cook GJ, Azad GK, Goh V. Imaging bone metastases in breast cancer: staging and response assessment. J Nucl Med. 2016;57(suppl 1):27S-33S

19. Warburg O, Wind F, Negelein E. The metabolism of tumours in the body. J Gen Physiol. 1927;8:519-530.

20. Oka S, Kanagawa M, Doi Y, Schuster DM, Goodman MM, Yoshimura H. PET tracer ${ }^{18} \mathrm{~F}$-fluciclovine can detect histologically proven bone metastatic lesions: a preclinical study in rat osteolytic and osteoblastic bone metastasis models. Theranostics. 2017;7:2048-2064.

21. Chen B, Wei P, Macapinlac HA, Lu Y. Comparison of ${ }^{18} \mathrm{~F}$-fluciclovine PET/CT and ${ }^{99 \mathrm{~m}} \mathrm{Tc}-\mathrm{MDP}$ bone scan in detection of bone metastasis in prostate cancer. Nucl Med Commun. 2019;40:940-946.

22. Afshar-Oromieh A, Zechmann CM, Malcher A, et al. Comparison of PET imaging with a ${ }^{68} \mathrm{Ga}$-labelled PSMA ligand and ${ }^{18} \mathrm{~F}$-choline-based PET/CT for the diagnosis of recurrent prostate cancer. Eur J Nucl Med Mol Imaging. 2014;41: 11-20.

23. Subramanian G, McAfee JG, Blair RJ, Kallfelz FA, Thomas FD. Technetium99m-methylene diphosphonate: a superior agent for skeletal imaging-comparison with other technetium complexes. J Nucl Med. 1975;16:744-755.

24. Utsunomiya D, Shiraishi S, Imuta M, et al. Added value of SPECT/CT fusion in assessing suspected bone metastasis: comparison with scintigraphy alone and nonfused scintigraphy and CT. Radiology. 2006;238:264-271.

25. Helyar V, Mohan HK, Barwick T, et al. The added value of multislice SPECT/CT in patients with equivocal bony metastasis from carcinoma of the prostate. Eur $J$ Nucl Med Mol Imaging. 2010;37:706-713.

26. Coombes RC, Dady P, Parsons C, et al. Assessment of response of bone metastases to systemic treatment in patients with breast cancer. Cancer. 1983;52:610-614

27. Doot RK, Muzi M, Peterson LM, et al. Kinetic analysis of ${ }^{18} \mathrm{~F}$-fluoride PET images of breast cancer bone metastases. J Nucl Med. 2010;51:521-527.

28. Yu EY, Duan F, Muzi M, et al. Castration-resistant prostate cancer bone metastasis response measured by ${ }^{18} \mathrm{~F}$-fluoride PET after treatment with dasatinib and correlation with progression-free survival: results from American College of Radiology Imaging Network 6687. J Nucl Med. 2015;56:354-360.

29. Azad GK, Siddique M, Taylor B, et al. Is response assessment of breast cancer bone metastases better with measurement of ${ }^{18} \mathrm{~F}$-fluoride metabolic flux than with measurement of ${ }^{18}$ F-fluoride PET/CT SUV? J Nucl Med. 2019;60:322-327.

30. Even-Sapir E, Metser U, Flusser G, et al. Assessment of malignant skeletal disease: initial experience with ${ }^{18} \mathrm{~F}$-fluoride PET/CT and comparison between ${ }^{18}$ F-fluoride PET and ${ }^{18}$ F-fluoride PET/CT. J Nucl Med. 2004;45:272-278.

31. Damle NA, Bal C, Bandopadhyaya GP, et al. The role of ${ }^{18} \mathrm{~F}$-fluoride PET-CT in the detection of bone metastases in patients with breast, lung and prostate carcinoma: a comparison with FDG PET/CT and ${ }^{99 \mathrm{~m} T c-M D P}$ bone scan. Jpn J Radiol. 2013;31:262-269.

32. Hillner BE, Siegel BA, Hanna L, Duan F, Shields AF, Coleman RE. Impact of ${ }^{18} \mathrm{~F}$-fluoride PET in patients with known prostate cancer: initial results from the National Oncologic PET Registry. J Nucl Med. 2014;55:574-581.

33. Hillner BE, Siegel BA, Hanna L, et al. Impact of ${ }^{18}$ F-fluoride PET on intended management of patients with cancers other than prostate cancer: results from the National Oncologic PET Registry. J Nucl Med. 2014;55:1054-1061.

34. Cook GJR, Parker C, Chua S, Johnson B, Aksnes AK, Lewington VJ. ${ }^{18}$ Ffluoride PET: changes in uptake as a method to assess response in bone metastases from castrate-resistant prostate cancer patients treated with ${ }^{223} \mathrm{Ra}$ chloride (Alpharadin). EJNMMI Res. 2011;1:4.

35. Murray I, Chittenden SJ, Denis-Bacelar AM, et al. The potential of ${ }^{223} \mathrm{Ra}$ and ${ }^{18} \mathrm{~F}$-fluoride imaging to predict bone lesion response to treatment with ${ }^{223} \mathrm{Ra}$ dichloride in castration-resistant prostate cancer. Eur J Nucl Med Mol Imaging. 2017;44:1832-1844.

36. Etchebehere EC, Araujo JC, Milton DR, et al. Skeletal tumor burden on baseline ${ }^{18} \mathrm{~F}$-fluoride PET/CT predicts bone marrow failure after ${ }^{223} \mathrm{Ra}$ therapy. Clin $\mathrm{Nucl}$ Med. 2016;41:268-273.

37. Hillner BE, Siegel BA, Hanna L, Duan F, Quinn B, Shields AF. ${ }^{18}$ F-fluoride PET used for treatment monitoring of systemic cancer therapy: results from the National Oncologic PET Registry. J Nucl Med. 2015;56:222-228.

38. Cook GJ, Houston S, Rubens R, Maisey MN, Fogelman I. Detection of bone metastases in breast cancer by ${ }^{18}$ FDG PET: differing metabolic activity in osteoblastic and osteolytic lesions. J Clin Oncol. 1998;16:3375-3379.

39. Dashevsky BZ, Goldman DA, Parsons M, et al. Appearance of untreated bone metastases from breast cancer on FDG PET/CT: importance of histologic subtype. Eur J Nucl Med Mol Imaging. 2015;42:1666-1673.

40. Shie P, Cardarelli R, Brandon D, Erdman W, Abdulrahim N. Meta-analysis: comparison of F-18 fluorodeoxyglucose-positron emission tomography and bone scintigraphy in the detection of bone metastases in patients with breast cancer. Clin Nucl Med. 2008;33:97-101.

41. Rong J, Wang S, Ding Q, Yun M, Zheng Z, Ye S. Comparison of ${ }^{18}$ FDG PET-CT and bone scintigraphy for detection of bone metastases in breast cancer patients: a meta-analysis. Surg Oncol. 2013;22:86-91.

42. Stafford SE, Gralow JR, Schubert EK, et al. Use of serial FDG PET to measure the response of bone-dominant breast cancer to therapy. Acad Radiol. 2002;9: 913-921.

43. Tateishi U, Gamez C, Dawood S, Yeung HW, Cristofanilli M, Macapinlac HA. Bone metastases in patients with metastatic breast cancer: morphologic and metabolic monitoring of response to systemic therapy with integrated PET/CT. Radiology. 2008;247:189-196.

44. Specht JM, Tam SL, Kurland BF, et al. Serial 2-[ $\left[{ }^{18} \mathrm{~F}\right]$ fluoro-2-deoxy-D-glucose positron emission tomography (FDG-PET) to monitor treatment of bone-dominant metastatic breast cancer predicts time to progression (TTP). Breast Cancer Res Treat. 2007;105:87-94.

45. Peterson LM, O'Sullivan J, Wu QV, et al. Prospective study of serial ${ }^{18} \mathrm{~F}-\mathrm{FDG}$ PET and ${ }^{18} \mathrm{~F}$-fluoride PET to predict time to skeletal-related events, time to progression, and survival in patients with bone-dominant metastatic breast cancer. J Nucl Med. 2018;59:1823-1830.

46. Krupitskaya Y, Eslamy HK, Nguyen DD, Kumar A, Wakelee HA. Osteoblastic bone flare on F18-FDG PET in non-small cell lung cancer (NSCLC) patients receiving bevacizumab in addition to standard chemotherapy. $J$ Thorac Oncol. 2009;4:429-431.

47. Morris MJ, Akhurst T, Larson SM, et al. Fluorodeoxyglucose positron emission tomography as an outcome measure for castrate metastatic prostate cancer treated with antimicrotubule chemotherapy. Clin Cancer Res. 2005;11:3210-3216.

48. Ceci F, Castellucci P, Graziani T, et al. ${ }^{11} \mathrm{C}$-choline PET/CT identifies osteoblastic and osteolytic lesions in patients with metastatic prostate cancer. Clin Nucl Med. 2015;40:e265-e270.

49. Evangelista L, Cimitan M, Zattoni F, Guttilla A, Zattoni F, Saladini G. Comparison between conventional imaging (abdominal-pelvic computed tomography and bone scan) and $\left[{ }^{18} \mathrm{~F}\right]$ choline positron emission tomography/computed tomography imaging for the initial staging of patients with intermediate-to high-risk prostate cancer: a retrospective analysis. Scand J Urol. 2015;49: 345-353.

50. Wondergem M, van der Zant FM, van der Ploeg T, Knol RJ. A literature review of ${ }^{18} \mathrm{~F}$-fluoride PET/CT and ${ }^{18} \mathrm{~F}$-choline or ${ }^{11} \mathrm{C}$-choline PET/CT for detection of bone metastases in patients with prostate cancer. Nucl Med Commun. 2013;34: 935-945.

51. Picchio M, Spinapolice EG, Fallanca F, et al. $\left[{ }^{11} \mathrm{C}\right]$ choline PET/CT detection of bone metastases in patients with PSA progression after primary treatment for prostate cancer: comparison with bone scintigraphy. Eur J Nucl Med Mol Imaging. 2012;39:13-26.

52. Beheshti M, Vali R, Waldenberger P, et al. Detection of bone metastases in patients with prostate cancer by ${ }^{18} \mathrm{~F}$ fluorocholine and ${ }^{18} \mathrm{~F}$ fluoride PET-CT: a comparative study. Eur J Nucl Med Mol Imaging. 2008;35:1766-1774.

53. Beheshti M, Vali R, Waldenberger P, et al. The use of F-18 choline PET in the assessment of bone metastases in prostate cancer: correlation with morphological changes on CT. Mol Imaging Biol. 2010;12:98-107.

54. Schwarzenböck SM, Eiber M, Kundt G, et al. Prospective evaluation of $\left[{ }^{11} \mathrm{C}\right]$ choline PET/CT in therapy response assessment of standardized docetaxel firstline chemotherapy in patients with advanced castration refractory prostate cancer. Eur J Nucl Med Mol Imaging. 2016;43:2105-2113. 
55. De Giorgi U, Caroli P, Scarpi E, et al. ${ }^{18}$ F-fluorocholine PET/CT for early response assessment in patients with metastatic castration-resistant prostate cancer treated with enzalutamide. Eur J Nucl Med Mol Imaging. 2015;42:1276-1283.

56. De Giorgi U, Caroli P, Burgio SL, et al. Early outcome prediction on ${ }^{18} \mathrm{~F}$-fluorocholine PET/CT in metastatic castration resistant prostate cancer patients treated with abiraterone. Oncotarget. 2014;5:12448-12458.

57. Zhou J, Gou Z, Wu R, Yuan Y, Yu G, Zhao Y. Comparison of PSMA-PET/CT, choline-PET/CT, NaF-PET/CT, MRI, and bone scintigraphy in the diagnosis of bone metastases in patients with prostate cancer: a systematic review and metaanalysis. Skeletal Radiol. 2019;48:1915-1924.

58. Lengana T, Lawal IO, Boshomane TG, et al. ${ }^{68} \mathrm{Ga}$-PSMA PET/CT replacing bone scan in the initial staging of skeletal metastasis in prostate cancer: a fait accompli? Clin Genitourin Cancer. 2018;16:392-401.

59. Pyka T, Okamoto S, Dahlbender M, et al. Comparison of bone scintigraphy and ${ }^{68} \mathrm{Ga}$-PSMA PET for skeletal staging in prostate cancer. Eur J Nucl Med Mol Imaging. 2016;43:2114-2121.

60. Rowe SP, Li X, Trock BJ, et al. Prospective comparison of PET imaging with PSMA-targeted ${ }^{18} \mathrm{~F}$-DCFPyL versus $\mathrm{Na}^{18} \mathrm{~F}$ for bone lesion detection in patients with metastatic prostate cancer. J Nucl Med. 2020;61:183-188.

61. Uprimny C, Svirydenka A, Fritz J, et al. Comparison of $\left[{ }^{68} \mathrm{Ga}\right] \mathrm{Ga}-\mathrm{PSMA}-11$ $\mathrm{PET} / \mathrm{CT}$ with $\left[{ }^{18} \mathrm{~F}\right] \mathrm{NaF} \mathrm{PET} / \mathrm{CT}$ in the evaluation of bone metastases in metastatic prostate cancer patients prior to radionuclide therapy. Eur J Nucl Med Mol Imaging. 2018;45:1873-1883.

62. Morin F, Beauregard JM, Bergeron M, et al. Metabolic imaging of prostate cancer reveals intrapatient intermetastasis response heterogeneity to systemic therapy. Eur Urol Focus. 2017;3:639-642.

63. Artigas C, Alexiou J, Garcia C, et al. Paget bone disease demonstrated on ${ }^{68} \mathrm{Ga}-$ PSMA ligand PET/CT. Eur J Nucl Med Mol Imaging. 2016;43:195-196.

64. Zacho HD, Petersen LJ. Bone flare to androgen deprivation therapy in metastatic, hormone-sensitive prostate cancer on ${ }^{68} \mathrm{Ga}$-prostate-specific membrane antigen PET/CT. Clin Nucl Med. 2018;43:e404-e406.
65. Lecouvet FE, Whole-body MR imaging: musculoskeletal applications. Radiology. 2016;279:345-365.

66. Wu LM, Gu HY, Zheng J, et al. Diagnostic value of whole-body magnetic resonance imaging for bone metastases: a systematic review and meta-analysis. J Magn Reson Imaging. 2011;34:128-135.

67. Mosavi F, Johansson S, Sandberg DT, Turesson I, Sörensen J, Ahlström H. Whole-body diffusion-weighted MRI compared with ${ }^{18} \mathrm{~F}-\mathrm{NaF}$ PET/CT for detection of bone metastases in patients with high-risk prostate carcinoma. AJR. 2012;199:1114-1120.

68. Jambor I, Kuisma A, Ramadan S, et al. Prospective evaluation of planar bone scintigraphy, SPECT, SPECT/CT, ${ }^{18} \mathrm{~F}-\mathrm{NaF}$ PET/CT and whole body $1.5 \mathrm{~T}$ MRI, including DWI, for the detection of bone metastases in high risk breast and prostate cancer patients: SKELETA clinical trial. Acta Oncol. 2016;55:59-67.

69. Luboldt W, Küfer R, Blumstein N, et al. Prostate carcinoma: diffusion-weighted imaging as potential alternative to conventional MR and ${ }^{11} \mathrm{C}$-choline PET/CT for detection of bone metastases. Radiology. 2008;249:1017-1025.

70. Heusner TA, Kuemmel S, Koeninger A, et al. Diagnostic value of diffusionweighted magnetic resonance imaging (DWI) compared to FDG PET/CT for whole-body breast cancer staging. Eur J Nucl Med Mol Imaging. 2010;37:10771086.

71. Perez-Lopez R, Mateo J, Mossop H, et al. Diffusion-weighted imaging as a treatment response biomarker for evaluating bone metastases in prostate cancer: a pilot study. Radiology. 2017;283:168-177.

72. Messiou C, Collins DJ, Morgan VA, Bianchini D, de Bono JS, de Souza NM. Use of apparent diffusion coefficient as a response biomarker in bone: effect of developing sclerosis on quantified values. Skeletal Radiol. 2014;43:205-208.

73. Eiber M, Takei T, Souvatzoglou M, et al. Performance of whole-body integrated ${ }^{18} \mathrm{~F}-\mathrm{FDG}$ PET/MR in comparison to PET/CT for evaluation of malignant bone lesions. J Nucl Med. 2014;55:191-197. 